\title{
IMPLEMENTASI PEMBELAJARAN BERBASIS ETHNO-EDUTAINMENT UNTUK MENINGKATKAN KARAKTER CINTA TANAH AIR SISWA SEKOLAH DASAR
}

\author{
Sekar Dwi Ardianti ${ }^{1 \bowtie}$, Savitri Wanabuliandari ${ }^{2}$, dan Moh. Kanzunnudin ${ }^{3}$ \\ 1 Prodi Pendidikan Guru Sekolah Dasar, FKIP Universitas Muria Kudus \\ 2 Prodi Pendidikan Matematika, FKIP Universitas Muria Kudus \\ 3 Prodi Pendidikan Bahasa dan Sastra Indonesia, FKIP Universitas Muria Kudus \\ Email: sekar.dwi.ardianti@umk.ac.id
}

\section{Info Artikel Abstract}

Sejarah Artikel:

Diterima 30 April 2019

Direvisi 30 Mei 2019

Disetujui 1 Juni 2019

\section{Keywords:}

Ethno, edutainment,

karakter, cinta tanah air

\begin{abstract}
The purpose of this study was to determine the improvement of the character of homeland love for elementary school students through the application of ethno-edutainment-based learning. This research is a pre-experimental study with one group pretest post test design research design. The sample used in this study was a fifth grade student of Muhammadiyah Kudus Elementary School with a purposive sampling technique. Data on students' love of homeland characters was obtained using student observation sheets and analyzed using normalized gain tests. The results showed that students' homeland love character scores after learning were higher, reaching 12.54 compared to before learning with a score of 6.36. The results of the normalized gain analysis show that the level of increase in the love character of the homeland students in the low category was $4.55 \%$, the medium category was $40.91 \%$, and the high category was $54.54 \%$. Classically, the value of normalized gain $\langle g>$ is $72 \%$ or 0.72 , which means that the interpretation of the increase in the character of love for the country is high
\end{abstract}

\section{Abstrak}

Tujuan penelitian ini adalah untuk mengetahui peningkatakan karakter cinta tanah air siswa sekolah dasar melalui penerapan pembelajaran berbasis ethno-edutainment. Penelitian ini merupakan penelitian pre-eksperimental dengan desain penelitian one group pretest post test design. Sampel yang digunakan dalam penelitian ini adalah siswa kelas V SD Muhammadiyah Kudus dengan teknik pengambilan sampel purposive sampling. Data karakter cinta tanah air siswa diperoleh dengan menggunakan lembar observasi siswa dan dianalisis dengan menggunakan uji normalized gain. Hasil penelitian menunjukkan bahwa skor karakter cinta tanah air siswa sesudah pembelajaran lebih tinggi yaitu mencapai 12,54 dibandingkan dengan sebelum pembelajaran dengan skor sebesar 6,36. Hasil analisis normalized gain diketahui bahwa tingkat peningkatan karakter cinta tanah air siswa pada kategori rendah sebesar 4,55\%, kategori sedang 40,91\%, dan kategori tinggi sebesar 54,54\%. Secara klasikal diperoleh nilai normalized gain $<\boldsymbol{g}>$ sebesar $72 \%$ atau 0,72 yang berarti tafsiran peningkatan karakter cinta tanah air termasuk kategori tinggi. 
Ardianti, Sekar Dwi., Wanabuliandari, Savitri., dan Kanzunnudin, Moh. IMPLEMENTASI PEMBELAJARAN BERBASIS ETHNO-EDUTAINMENT UNTUK ...

REFLEKSI EDUKATIKA : Jurnal Ilmiah Kependidikan, Volume 9, Nomor 2, Juni 2019, hlm 204-209

\section{PENDAHULUAN}

Kemajuan suatu bangsa ditentukan oleh pembangunan karakter di dalamnya. Presiden Indonesia pertama Ir. Soekarno menyatakan bahwa "Bangsa ini harus dibangun dengan mendahulukan pembangunan karakter, karena pembangunan karakter inilah yang akan membuat Indonesia menjadi bangsa yang besar, maju, jaya dan bermartabat". Fahrudi dan Wiratmoko (2016) Sekarang ini, Indonesia mengalami krisis karakter dikarenakan rendahnya pendidikan karakter. Samani et al (2016) menjelaskan bahwa pelaksanaan pendidikan karakter di Indonesia dirasakan mendesak untuk dilakukan berdasarkan gambaran situasi di masyarakat maupun situasi dunia pendidikan. Disiplin, tertib, budaya antri, budaya baca, budaya hidup bersih dan sehat sampai budaya mengahargai juga mulai luntur. Kebanggaan terhadap jati diri dan kekayaan kebudayaan negara sendiri juga masih rendah terbukti dengan mudahnya masyarakat menerima produk dan budaya asing tanpa seleksi. Generasi muda pada masa sekarang ini banyak terpengaruh dengan kebudayaan asing yang masuk di Indonesia. Hal tersebut ditunjukkan dengan semakin meningkatnya jumlah generasi muda yang mengikuti perkembangan dan meniru kebudayaan asing tanpa mempertimbangkan baik buruknya budaya tersebut.

Di era globalisasi ini masyarakat perlu mewaspadai adanya unsur-unsur budaya asing yang dapat menyebabkan lunturnya cinta tanah air. Lunturnya cinta tanah air ini akan menyebabkan kekhawatiran terhadap masa depan generasi muda. Generasi muda saat ini juga kurang mengenal budaya dan seni di Indonesia. Penelitian Mariani (2012) terhadap komunitas korea pop fandom malang menyebutkan bahwa ada kekhawatiran terhadap generasi muda saat ini, karena generasi muda saat ini lebih menyukai budaya korea daripada budaya Indonesia. Tondo (2009) menjelaskan bahwa bahasa daerah saat ini berada di ambang kepunahan, dikarenakan makin berkurang penutur aslinya. Ini menunjukkan bahwa bahasa daerah perlu dihidupkan lagi untuk memupuk cinta tanah air di masyarakat. Oleh karena itu, hendaknya pemerintah lebih memperhatikan penanamkan karakter cinta tanah air ini sejak dini.

Berdasarkan Undang-Undang Nomor 20 tahun 2003 pasal 3 tentang Sistem Pendidikan
Nasional menyebutkan bahwa pendidikan nasional bertujuan untuk mengembangkan dan membentuk watak, karakter serta peradaban bangsa yang bermartabat dalam rangka mencerdaskan kehidupan bangsa. Rumusan tujuan pendidikan ini berarti juga menjadi dasar dalam pengembangan pendidikan budaya dan karakter bangsa. Salah satu karakter yang perlu dikembangkan pada siswa adalah cinta tanah air. Hal tersebut dikarena saat ini karekter cinta tanah air masih kurang. Penanaman karakter cinta tanah air dilakukan, mengingat bahwa bangsa ini memerlukan generasi yang lebih baik di masa yang akan datang. Menanamkan karakter cinta tanah air dapat diawali dengan mengenal, memahami, serta menghargai budaya lokal yang ada di sekitarnya. Pendidikan yang dilandasi dengan kaidah budaya yang kuat akan membuat siswa tidak mudah terpengaruh budaya dari luar, sehingga mereka mampu untuk mempertimbangkan baik tidaknya budaya luar tersebut.

Salah satu cara yang dapat dilakukan adalah dengan pembelajaran ethno -edutainment. Ethno berasal dari kata ethnic yang berarti berkaitan dengan budaya lokal yang ada di masyarakat yang masih bersifat umum. Menurut Sutrisno dalam Hamid (2011) menyebut bahwa pembelajaran yang menyenangkan dapat diakukan dengan demonstrasi, permainan, bermain peran dan humor. Ini berarti bahwa pembelajaran Ethno-edutainment merupakan pembelajaran tentang budaya lokal yang dikemas dengan permainan yang menyenangkan. Penerapan pembelajaran berbasis ethnoedutainment dapat menghubungkan kondisi nyata di lingkungan sekitar dengan materi pembelajaran. Hal tersebut sesuai dengan pendapat Khoiri (2016) yang menyatakan bahwa pembelajaran dengan menghubungkan keunggulan daerah dengan materi ajar dapat membantu siswa dalam mencapai tujuan pembelajaran. Wanabuliandari, et al (2018) menjelaskan bahwa penanaman karakter cinta tanag air dapat dilakukan dengan menggunakan modul. Penerapan pembelajaran berbasis ethnoedutainment diharapkan dapat meningkatkan karakter cinta tanah air siswa sekolah dasar.

\section{METODE PENELITIAN}

Penelitian ini merupakan penelitian preeksperimental dengan desain penelitian one 
Ardianti, Sekar Dwi., Wanabuliandari, Savitri., dan Kanzunnudin, Moh.

IMPLEMENTASI PEMBELAJARAN BERBASIS ETHNO-EDUTAINMENT UNTUK ...

REFLEKSI EDUKATIKA : Jurnal Ilmiah Kependidikan, Volume 9, Nomor 2, Juni 2019, hlm 204-209

group pretest post test design. Desain penelitian tersebut digambarkan oleh Ruseffendi (2010) sebagai berikut.

$$
\mathrm{O} \quad \mathrm{X} \quad \mathrm{O}
$$

Keterangan:

$\mathrm{O}:$ Pretest dan posttest siswa

$\mathrm{X}$ : Pembelajaran berbasis ethno-edutainment

Sampel yang digunakan dalam penelitian ini yaitu siswa kelas V SD Muhammadiyah Kudus. Pengambilan sampel dilakukan dengan teknik purposive sampling. Hal tersebut dikarenakan siswa kelas $\mathrm{V}$ usia sekolah dasar memiliki karakteristik cenderung menyukai dengan pembelajaran yang bernuansa hiburan dan juga sudah memiliki bekal pengetahuan mengenai kebudayaan dan kearifan lokal daerah masing-masing.

Data karakter cinta tanah air siswa diperoleh dengan menggunakan lembar observasi karakter cinta tanah air siswa. Indikator karakter cinta tanah air yang digunakan dalam menyusun lembar observasi siswa yaitu mengagumi posisi geografis wilayah Indonesia dalam perhubungan laut dan udara dengan negara lain, mengagumi kekayaan budaya dan seni di Indonesia, mengagumi keragaman suku, etnis, dan bahasa sebagai keunggulan yang hadir di wilayah negara Indonesia, mengagumi sumbangan produk pertanian, perikanan, flora, dan fauna Indonesia bagi dunia, mengagumi peran hutan Indonesia bagi dunia, dan mengagumi peran laut dan hasil laut Indonesia bagi bangsa-bangsa di dunia (Kemendikbud, 2010). Indikator karakter cinta tanah air tersebut diturunkan menjadi 15 aspek pengamatan dalam lembar observasi siswa.

Data dianalisis secara kuantitatif dengan menggunakan uji normalized gain (N-gain) untuk mengetahui seberapa besar peningkatan karakter cinta tanah air siswa sekolah dasar dengan diterapkannya pembelajaran berbasis ethno-edutainment. Peningkatan karakter cinta tanah air siswa dihitung berdasarkan nilai pretest dan post test siswa dengan menggunakan rumus normalized gain sebagai berikut (Hake, 1998:65).

$$
\langle g\rangle=\frac{\text { Spost }- \text { Spre }}{\text { Smaks }- \text { Spre }} \times 100 \%
$$

Keterangan:

Spost $=$ Skor post test

Spre = Skor pretest

Smaks $=$ Skor maksimal (15)

Hasil perhitungan dengan menggunakan rumus normalized gain selanjutnya diterjemahkan dengan kriteria perolehan skor normalized gain $\langle g\rangle$ pada Tabel 1 berikut ini (Hake, 1998:65).

Tabel 1. Kriteria Perolehan Normalized Gain $<g>$

\begin{tabular}{ll}
\hline Normalized gain $\langle g\rangle$ & Kriteria \\
\hline$\langle g\rangle<0,3$ & Rendah \\
$0,3 \leq\langle g\rangle<0,7$ & Sedang \\
$\langle g\rangle \geq 0,7$ & Tinggi \\
\hline
\end{tabular}

\section{HASIL DAN PEMBAHASAN}

Hasil yang diperoleh dalam penelitian ini berupa skor karakter cinta tanah air yang diukur melalui lembar observasi karakter cinta tanah air siswa sekolah dasar. Pengamatan dilakukan kepada siswa sebelum diterapkannya pembelajaran berbasis ethno-edutainment (pretest) dan diakhir pembelajaran berbasis ethno-edutainment (post test).

Skor karakter cinta tanah air siswa sebelum dan sesudah penerapan pembelajaran berbasis ethno-edutainment disajikan dalam Tabel 2 berikut ini.

Tabel 2. Rekapitulasi Skor Karakter Cinta tanah air Sebelum dan Sesudah Pembelajaran.

\begin{tabular}{lll}
\hline \multirow{2}{*}{ Komponen } & \multicolumn{2}{l}{ Skor Cinta tanah air } \\
\cline { 2 - 3 } & Sebelum & Sesudah \\
\hline Rata-rata & 6,36 & 12,54 \\
Skor tertinggi & 9 & 14 \\
Skor terendah & 5 & 9 \\
\hline
\end{tabular}

Perolehan skor karakter cinta tanah air siswa sekolah dasar sesudah pembelajaran secara umum lebih tinggi dibandingkan dengan skor sebelum pembelajaran. Hal tersebut dapat terlihat pada skor rata-rata karakter cinta tanah air siswa sesudah pembelajaran mencapai 12,54 dan sebelum pembelajaran hanya sebesar 6,36. Skor tersebut selanjutnya dianalisis secara statistik dengan menggunakan uji normalized gain untuk mengetahui seberapa besar peningkatan skor 
Ardianti, Sekar Dwi., Wanabuliandari, Savitri., dan Kanzunnudin, Moh. IMPLEMENTASI PEMBELAJARAN BERBASIS ETHNO-EDUTAINMENT UNTUK ...

REFLEKSI EDUKATIKA : Jurnal Ilmiah Kependidikan, Volume 9, Nomor 2, Juni 2019, hlm 204-209

karakter cinta tanah air siswa sebelum dan sesudah pembelajaran.

Hasil perhitungan untuk peningkatan karakter cinta tanah air dengan menggunakan uji normalized gain dapat dilihat pada Tabel 3 berikut ini.

Tabel 3. Hasil Peningkatan Karakter Cinta tanah air

\begin{tabular}{ll}
\hline Kriteria & Persentase \\
\hline Rendah & $4,55 \%$ \\
Sedang & $40,91 \%$ \\
Tinggi & $54,54 \%$ \\
\hline
\end{tabular}

Berdasarkan Tabel 3 dapat diketahui bahwa hasil peningkatan karakter cinta tanah air siswa sekolah dasar dengan tingkat peningkatan kategori rendah sebesar 4,55\%, kategori sedang sebesar 40,91 \%, dan kategori tinggi sebesar $54,54 \%$. Secara klasikal diperoleh nilai normalized gain $<\boldsymbol{g}>$ sebesar $72 \%$ atau 0,72 yang berarti tafsiran peningkatan karakter cinta tanah air termasuk dalam kategori tinggi.

Peningkatan karakter cinta tanah air siswa sekolah dasar dikarenakan penerapan pembelajaran berbasis ethno-edutainment yang mengajak siswa untuk lebih dekat dengan budaya lokal yang ada di lingkungan sekitar. Riset ini senada dengan penelitian Hasanah (2016) berpendapat bahwa wawasan dari budaya lokal dapat mengembangkan potensi yang dimiliki oleh siswa dan dapat menanamkan karakter cinta tanah air. Pembelajaran berbasis ethnoedutainment mengajak siswa untuk belajar secara langsung di lingkungan dalam suasana yang menyenangkan. Pengalaman belajar yang diperoleh siswa secara langsung dari lingkungan selain dapat meningkatkan karakter cinta tanah air juga dapat memberikan efek positif terhadap hasil belajar siswa. Penelitian ini di dukung hasil riset dari Arfinanwati (2016) berpendapat bahwa pembelajaran berbasis etno yang berkaitan dengan kehidupan sehari-hari dapat membantu siswa dalam memahami sebuah konsep.

Pembelajaran berbasis ethno-edutainment sebagai pembelajaran merupakan pembelajaran yang disajikan secara menarik dan menyenangkan dengan menghubungkan materi belajar siswa dengan konten budaya yang ada di lingkungan sekitar. Ethno-edutainment berasal dari kata ethno dan edutainment. Ethno sebagai penggunaan budaya local sedangkan edutainment merupakan pembelajaran yang menarik dan menyenangkan. Riset Pratiwi, Ardianti \& Kanzunnudin (2018) mengemukakan bahwa edutainment sebagai desain pembelajaran dimana muatan pembelajaran dikombinasi dengan hiburan yang bersifat menyenangkan. Ardianti, Pratiwi \& Kanzunnudin (2017) juga menyatakan bahwa edutainment sebagai pembelajaran yang dikemas secara menarik dan menyenangkan melalui kegiatan, media, ataupun bahan ajar yang digunakan tanpa melupakan tujuan pembelajaran. Pembelajaran yang menarik dan menyenangkan tersebut cocok digunakan untuk siswa sekolah dasar mengingat sifat dasar alamiah anak usia sekolah dasar adalah bermain. Pembelajaran berbasis ethno-edutainment dapat membantu guru dalam menyisipkan karakter cinta tanah air siswa dalam kegiatan pembelajaran. Yunus (2013) menyatakan pembelajaran berbasis budaya lokal dapat membantu dalam pembangunan karakter suatu bangsa. Amrullah, Hadisaputo dan Supardi (2018) menyebutkan bahwa modul dapat membantu untuk mengintegrasikan karakter.

Hasil penelitian ini senada pula dengan riset Ismaya dan Romadlon (2017) yang menunjukkan bahwa dalam rangka membentuk karakter semangat kebangsaan anggota pramuka Ambalan Kyai Mojo dan Nyi Ageng Serang, strategi yang ditempuh yaitu dengan mengadakan latihan rutin. Ada pula latihan Satuan Karya Pramuka (SAKA) untuk mendidik dan melatih anggotanya sesuai minat.

\section{SIMPULAN}

Berdasarkan hasil penelitian disimpulkan bahwa pembelajaran berbasis ethno-edutainment dapat meningkatkan karakter cinta tanah air siswa. Peningkatan karakter cinta tanah air dengan skor peningkatan kategori rendah sebesar $4,55 \%$, kategori sedang sebesar 40,91\%, dan kategori tinggi sebesar 54,54\%. Secara klasikal diperoleh nilai normalized gain $<\boldsymbol{g}>$ sebesar 72 $\%$ atau 0,72 yang berarti tafsiran peningkatan karakter cinta tanah air yang terjadi termasuk kategori tinggi. 
Ardianti, Sekar Dwi., Wanabuliandari, Savitri., dan Kanzunnudin, Moh.

IMPLEMENTASI PEMBELAJARAN BERBASIS ETHNO-EDUTAINMENT UNTUK ...

REFLEKSI EDUKATIKA : Jurnal Ilmiah Kependidikan, Volume 9, Nomor 2, Juni 2019, hlm 204-209

\section{DAFTAR PUSTAKA}

Amrullah, A., Hadisaputo, S., \& Supardi, K. I. Pengembangan Chemireligiousa Terintegrasi Pendidikan Karakter Bervisi SETS. Jurnal Inovasi Pendidikan Kimia, 11 (1): 1872-1883

Ardianti, S.D., Pratiwi, I.A., \& Kanzunnudin, M. (2017). Implementasi Project Based Learning (PjBL) Berpendekatan Science Edutainment Terhadap Kreativitas Siswa. Jurnal Refleksi Edukatika. Jurnal Refleksi Edukatika, 7 (2), 145-150.

Arfianawati S, Sudarmin, \& Sumarni, W. 2016. Model Pembelajaran Kimia Berbasis Etnosains untuk Meningkatkan Kemampuan Berpikir Kritis Siswa. Jurnal Pengajaran MIPA. 21(1).

Fahrudi, E. Z., \& Wiratmoko, D. 2016. Peran Pendidikan Sebagai Pondasi Penumbuhan Karakter Bangsa Indonesia. Prosiding Seminar Nasional Reforming Pedagogy 2016.

Hake, R.R. 1998. Interactive-engagement versus traditional methods: A six-thousandstudent survey of mechanics test data for introductory physics courses. American Journal of Physics. 66 (1): 64-74.

Hamid S. 2011. Metode Edutainment. Yogyakarta: Diva Press.

Hasanah D \& Prihati Y. 2016. Pengembangan Modul Fisika Berbasis Potensi Lokal Kerajinan Gerabah Kasongan Yogyakarta Pada Materi Usaha Dan Energi Untuk Siswa SMA. Prosiding Seminar Nasional Pendidikan Sains: Peningkatan Kualitas Pembelajaran Sains dan Kompetensi Guru melalui Penelitian \& Pengembangan dalam Menghadapi Tantangan Abad-21. Surakarta.

Ismaya, Erik Aditia dan Romadlon, Farid Noor. 2017. Strategi Membentuk Karakter Semangat Kebangsaan Anggota Ambalan Kyai Mojo Dan Nyi Ageng Serang. Jurnal Refleksi Edukatika, 7 (2), 140-144.
Kementrian Pendidikan Nasional, Badan Penelitian dan Pengembangan Pusat Kurikulum. 2010. Bahan Pelatihan Penguatan Metodologi Pembelajaran 127 Berdasarkan Nilai-Nilai Budaya Untuk Membentuk Daya Saing Dan Karakter Bangsa. Pengembangan Pendidikan dan Karakter Bangsa. Jakarta: Kemendiknas.

Khoiri, A. 2016. Local Wisdom PAUD to Grow Student's Soft Skills (Study Cash: Development RKH On Science Learning). Indonesian Journal of Early Childhood Education Studies, 5 (1): 1417.

Mariani D. 2012. Sikap Nasionalisme Di Kalangan Pecinta Lagu dan Penyanyi Korea Yang Tergabung dalam Komunitas Korea POP Fandom Malang. Jurnal Pendidikan Kewarganegaraan, 1(1)

Pratiwi, I.A., Ardianti, S.D., \& Kanzunnudin, M. (2018). Peningkatan Kemampuan Kerjasama Melalui Model Project Based Learning (PjBL) Berbantuan Metode Edutainment Pada Mata Pelajaran Ilmu Pengetahuan Sosial. Jurnal Refleksi Edukatika, 8(2), 177-182.

Ruseffendi, E.T. (2010). Dasar-dasar Penelitian Pendidikan \& Bidang Non-Eksakta Lainnya. Bandung: Tarsito.

Rusman. (2011). Model-Model Pembelajaran. Jakarta: Rajawali Pers.

Samani M, Hariyanto. 2016. Konsep dan Model Pendidikan Karakter. Bandung: PT Remaja Rosdakarya.

Tondo H. 2009. Kepunahan Bahasa-Bahasa Daerah: Faktor Penyebab dan Implikasi Etnolinguistik. Jurnal Masyarakat dan Budaya. 11(2).

Wanabuliandari, S., Ardianti, S., Saptono, S., Alimah, S., \& Kurniasih., N. (2018). Edutainment Module based on Local Culture of Eastern Pantai Utara, Central Java Reviewed From Experts. International Journal of Engineering \& 
Ardianti, Sekar Dwi., Wanabuliandari, Savitri., dan Kanzunnudin, Moh.

IMPLEMENTASI PEMBELAJARAN BERBASIS ETHNO-EDUTAINMENT UNTUK ...

REFLEKSI EDUKATIKA : Jurnal Ilmiah Kependidikan, Volume 9, Nomor 2, Juni 2019, hlm 204-209

Technology, 7 (2.14): 242-245.

Yunus, R.. 2013. Transformasi Nilai-Nilai Budaya Lokal Sebagai Upaya
Pembangunan Karakter Bangsa. Jurnal Penelitian Pendidikan. Jurnal Penelitian Pendidikan, 13 (1): 67-79. 